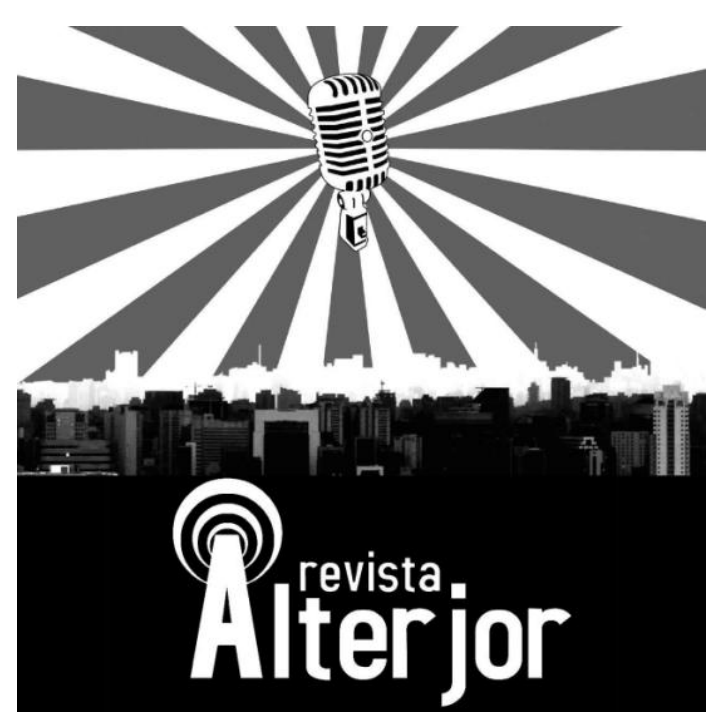

\title{
A PRODUÇÃO JORNALÍSTICA EM FAVOR DA COMUNIDADE: ASPECTOS DO PROGRAMA CARAVANA DO ESPORTE
}

\author{
Tiago Brant de Carvalho Falcão ${ }^{1}$
}

RESUMO: Este artigo tem como objetivo identificar e analisar as razões que levam à produção de um programa jornalístico como ferramenta de comunicação para um movimento de ação e mobilização social pelo esporte educacional, disseminando os princípios do olimpismo e da educação integral. O objeto de estudo é o programa "Caravana do Esporte", veiculado mensalmente pelo canal ESPN Brasil, num universo dominado pelo esporte de alto rendimento, pelo entretenimento e pelo crescente culto às celebridades do esporte.

PALAVRAS-CHAVE: Esporte e Educação. Jornalismo Esportivo. Olimpismo. Televisão.

\footnotetext{
${ }^{1}$ Jornalista. E-mail: tiagobfalcao@gmail.com

Revista ALTERJOR

Grupo de Estudos Alterjor:Jornalismo Popular e Alternativo (ECA-USP)

Ano 07 Volume 02 Edição $14 \quad$ Julho-Dezembro de 2016
}

Avenida Professor Lúcio Martins Rodriģues, 443, Cidade Universitária, São Paulo, CEP: 05508-020 


\section{Introdução}

O modelo atual de produção de conteúdo esportivo na televisão brasileira privilegia o esporte de alto rendimento, com enorme destaque para o futebol, e parece mais preocupado em transformar o esporte em entretenimento barato que em promover os princípios do olimpismo, mesmo às vésperas da realização dos primeiros Jogos Olímpicos da América do Sul, no Rio de Janeiro, em 2016. O grande público consome o esporte como entretenimento e diversão, segundo a prática das grandes empresas jornalísticas, que preferem não aprofundar debates mais sérios em nome da pretensa leveza que caracteriza os temas abordados nas reportagens sobre esporte veiculadas pela mídia (PADEIRO, 2015).

Mas o esporte não se resume a isso. É um poderoso instrumento de educação e deveria ser encarado com mais seriedade por nossos governantes e legisladores. Não por acaso, o assunto desperta paixões e provoca mudanças consideráveis na percepção e na auto estima nacional sempre que grandes eventos esportivos acontecem.

Mas o fato básico é que a esfera do esporte entroniza no mundo moderno formas legítimas de medição de força e de comportamento conflitivo e agonístico que, embora tenham uma moldura moderna, racional e empresarial, são capazes de despertar em circunstâncias especiais ou apropriadas esses valores relativamente adormecidos e essenciais à renovação dos laços sociais e da própria sociabilidade. Por isso o esporte e, dentro dele, o futebol, pode ser facilmente ligado a cosmologia locais. Assim, para Nelson Rodrigues, por exemplo, o escrete nacional do Brasil transforma o povo brasileiro em profeta, ávido leitor e patriota, dotando-o da capacidade de falar diretamente com Deus. (DAMATTA, IN REVISTA USP 22, 1994, p. 14-15).

Mais que a prática esportiva em si, o que importa são os valores e os ideais implicados. A partir da compreensão dos aspectos intrínsecos que envolvem o esporte incluídos a preparação física e mental, a dedicação, a disciplina, o comprometimento, a saúde, a nutrição e as motivações que levam à prática esportiva, além do círculo social que se forma em torno da atividade - é possível compreender a importância do esporte na formação do ser humano. Percebendo isso, o Barão Pierre de Coubertin reeditou os Jogos Olímpicos da Antiguidade em 1896, para torná-los uma celebração do esporte e da vida. "O que importa nos Jogos Olímpicos não é vencer e sim participar. O que 
importa na vida não é o triunfo, e sim a luta." (COUBERTIN apud COUSINEAU, 2004, p. 37).

Valores como a excelência, a amizade e o respeito, comuns ao olimpismo, deveriam nortear o trabalho dos jornalistas esportivos, afim de aproveitar o momento olímpico para abrir espaço às boas práticas, às modalidades menos conhecidas e aos benefícios que o esporte pode trazer à sociedade, já que as grandes empresas de comunicação, entre elas as informativas, tem influência direta no desenvolvimento esportivo, por serem o principal canal de divulgação, ao lado do Estado, de práticas e eventos. Pela mídia, o esporte torna-se espetáculo, entretenimento e também informação, despertando grande carga de interesse no público e, assim, transformando atletas em ídolos, numa sociedade carente de boas referências. São inúmeros os exemplos de atletas que influenciam positivamente uma nação pela simples divulgação de seus exemplos pessoais. O que explica esse fenômeno, além do talento e da dedicação destes atletas, é o amor que sentem pelo esporte. Um amor capaz de contaminar e influenciar o grande público, desde que este tome conhecimento das belas histórias de superação que a maioria dos atletas carrega.

Às vezes, os sentidos do esporte são constituídos pelo atletaque, visto como herói ou semideus, é fonte de inspiração. Pode-se constatar uma verdadeiraveneração pela figura dos esportistas que, por terem-se destacado em suasrespectivasmodalidades, tornam-se alvo de atenções. (TAMBUCCI,2011, p. 669)

Apesar do enorme apelo social, no entanto, o esporte como ferramenta de educação sempre foi subestimado pela grande mídia e, o que é pior, pelo sistema educacional brasileiro. Programas sobre esporte e educação costumam passar longe das grades de programação, mas uma grata exceção é o "Caravana do Esporte" que, desde 2005, coloca na grade da ESPN Brasil um especial sobre esporte, educação e inclusão social, fomentando a mobilização pelo esporte educacional, pelo direito da criança educação, à cultura, ao esporte e ao lazer.

Diante desta realidade, o artigo pretende compreender os processos de produção do programa "Caravana do Esporte", como forma de desenvolver o esporte e a educação, sem depender da agenda e dos propósitos da mídia estabelecida, mais 
interessada em audiência e contratos publicitários, que no desenvolvimento do esporte sob a perspectiva de valores como ética, cidadania, educação e interesse público.

\section{Objeto}

Criado em 2005 pela aliança entre o Instituto Esporte e Educação, o canal de TV ESPN Brasil e o UNICEF, a "Caravana do Esporte" já atendeu diretamente 187.000 crianças e adolescentes, além de 18.000 professores da rede pública de ensino em 75 municípios de 16 estados brasileiros. A iniciativa reúne professores, atletas, instituições e organizações esportivas da sociedade civil em torno de um evento esportivo educacional, pela formação de professores e educadores locais em esporte educacional e pela articulação política através do envolvimento da comunidade e do poder público na construção de planos estratégicos para a continuidade, com ações norteadas pelos princípios: inclusão de todos, educação integral, construção coletiva, respeito à diversidade, valorização da cultura local e autonomia. A metodologia é aplicada pelo Instituto Esporte e Educação (IEE), e todas as atividades são registradas por uma equipe de jornalistas e técnicos do canal de televisão ESPN Brasil que transformam o conjunto de ações da "Caravana do Esporte" num documentário jornalístico com uma hora de duração, exibido mensalmente na grade de programação da emissora ${ }^{2}$.

\section{Discussões em torno da cobertura esportiva}

O percurso teórico se desenvolve a partir da análise dos princípios apregoados para a prática de um bom jornalismo esportivo e o porque de encontrarmos tão poucos exemplos dessa prática jornalística no presente.

A primeira referência é Pierre Bordieau (1997). O autor aborda questões essenciais para o estudo da imprensa e da produção jornalística atual. Sua análise rejeita a explicação corrente de que a ideologia dos dirigentes dos meios de comunicação é a principal responsável pelo que é produzido pela imprensa, mostrando diversas outras variáveis que influenciam o campo da informação jornalística, incluindo o óbvio: “É

\footnotetext{
${ }^{2}$ Disponível em: http://www.esporteeducacao.org.br/?q=node/41. Acesso em : 05 Jul. 2016
} 
verdade que, em última instância, pode-se dizer que o que se exerce sobre a televisão é a pressão econômica" (BOURDIEU, 1997, pg. 19). E assim, na urgência de manter o funcionamento de uma estrutura midiática construída sobre alicerces econômicos e interesses comerciais, há uma grande quantidade de informações sem relevância, mais próximas do entretenimento que do bom jornalismo (PADEIRO, 2015).

No ambiente competitivo em que funcionam as atuais redações dos grandes veículos de imprensa, os jornalistas cometem uma espécie de autocensura ao comparar seus textos e suas produções com as de outros profissionais da área, procurando adequar seu conteúdo à norma vigente. $\mathrm{O}$ resultado são informações e abordagens homogêneas. Nesse contexto, falta autonomia ao comunicador, reflexo das relações sociais entrejornalistas. Relações de concorrência, mas também de conivência e cumplicidade objetiva. (BOURDIEU, 1997)

Em seu livro “A Nova Televisão"(1996), Nelson Hoineff nos ajuda a compreender a importância da televisão e seu sucesso enquanto veículo de comunicação de massa na vida dos brasileiros.

Talvez em nenhuma outra sociedade do mundo o veículo tenha se tornado tão importante. Esse conjunto único de circunstâncias - má distribuição da renda nacional, baixo nível de educação da população, concentracionismo da teledifusão, alta qualidade da teledramaturgia, prolongado período totalitáriojustamente nas décadasde60e 70, e a existênciade uma hegemonia cultural mítica numa população altamente pulverizada porregiões de identidades culturais bem distintas entre si - fez com que no Brasil a televisão se transformasse, mais que em representação, na própria expressão da realidade.(HOINEFF, 1996, p. 28-29)

Ao aproximar o debate em torno da cobertura jornalística esportiva no Brasil, vale a pena ler a reportagem ganhadora do Prêmio Tim Lopes de jornalismo investigativo, "O Lugar do Esporte na Comunicação Pública", de Priscila Crispi publicada na "Revista do Conselho Curador EBC", edição de julho de 2014.

A cobertura esportiva no Brasil é um serviço tão incorporado ao cotidiano de redações e público que discuti-la pode parecer redundante. Mas, é o caso de se pensar: a dimensão cultural, econômica e política do desporto tem sido alvo de análise profunda pelas equipes jornalísticas? $\mathrm{O}$ debate em torno dos direitos de transmissão está esgotado? Qual o papel da mídia na engrenagem que faz o negócio esportivo prosperar? Tantas questões em aberto apontam para a necessidade de levar a discussão em torno da 
cobertura de esportes mais a sério. (Revista do Conselho Curador EBC, Julho de 2014, p.11).

Crispi relata um entrelaçamento demasiado entre o jornalismo esportivo e o entretenimento, gerando uma cobertura esportiva desvinculada de abordagens mais profundas. O problema não é exclusivamente brasileiro, visto que o esporte é associado ao espetáculo e a temas mais leves,destinados a entreter o público, mais que informá-lo.

Para se produzir um bom jornalismo esportivo, é fundamental entender e relatar os aspectos sociais, políticos e econômicos envolvidos no contexto da prática esportiva, algo que acontece com frequência cada vez mais esparsa. Nesse sentido, Heródoto Barbeiro e Patrícia Rangel já alertavam, na obra Manual do Jornalismo Esportivo, de 2006, sobre a proximidade perniciosa do entretenimento com o jornalismo esportivo.

Ele (o jornalismo esportivo) se confunde, frequentemente, com puro entretenimento. Isto, por seu lado, propicia o aparecimento de alguns poucos 'coroados' e o envolvimento com outras atividades incompatíveis com a prática do jornalismo, como agenciamento de publicidade, marketing e política privada dos clubes, federações, confederações e empresas. (BARBEIRO \& RANGEL, 2006, p. 13).

O desafio à produção do bom jornalismo esportivo pode ser traduzido pela disputa por audiência e visibilidade, que oferece vantagem comercial aos detentores dos direitos de transmissão dos principais eventos esportivos de alta performance. $\mathrm{O}$ professor David Rowe (2004) acredita que é preciso ter consciência em relação à forma como as empresas de mídia brigam pelos direitos de transmissão do esporte, e de como as ligas esportivas competem para vender os mesmos direitos pelo mais alto valor, enquanto patrocinadores e anunciantes buscam a mais abrangente e favorável forma de divulgar produtos e ideias através do esporte. “É possível se tornar tão preocupado com assuntos econômicos de propriedade, controle e maximização do lucro que as características específicas da mídia esportiva desaparecem do foco" (ROWE, 2004, p. 12).

Para manter em funcionamento uma estrutura midiática baseada em interesses comerciais, abre-se mão do interesse social em nome de uma produção jornalística que enxerga esporte como mercadoria de consumo e diversão, desperdiçando o espaço oferecido pela mídia para estabelecer o esporte comooportunidade educacional, social e 
cultural. Segundo o professor Luciano Maluly (2013), o Jornalismo é o espaço ideal para essa discussão e deve servir como referência para uma possível modificação na estrutura atual de cobertura esportiva, principalmente em tempos de Jogos Olímpicos.

Os repórteres começam a ampliar os espaços de cobertura, com o foco indoalém dos campos e ginásios. A pauta contempla os diversos locais de prática, incluindo os voltados à atividade física, fazendo referência ao lazer, à saúde e à educação. (MALULY, 2013, p. 03).

A bibliografia que abrange a produção de conteúdo esportivo para televisão e, mais especificamente, a cobertura esportiva e olímpica ainda é extensa, mas, por hora, este artigo pretende compreender as razões e os meios empregados na produção de nosso objeto de estudo, o programa "Caravana do Esporte". Por isso entrevistamos um dos criadores do programa, o jornalista José Trajano e a responsável por sua produção, a jornalista Adriana Saldanha, tendo como pano de fundo o contexto supracitado e a produção do bom jornalismo esportivo, baseado nos princípios do olimpismo.

\section{Ações do Caravana do Esporte}

Segundo José Trajano, diretor de jornalismo dos canais ESPN entre 1995 e 2012, o projeto fazia parte de algo maior, destinado ao governo federal no início do primeiro mandato do presidente Luis Inácio Lula da Silva.

Mas nada foi pra frente. Como esse era um projeto em que eu acreditava muito, resolvemos fazer por nossa conta. Aí eu chamei a Adriana Saldanha e a Ana Mozer, falei sobre o projeto, elas colocaram de pé e tocaram. Eu criei e elas fizeram acontecer, sem elas não haveria projeto. (TRAJANO, 2016)

A produtora e jornalista Adriana Saldanha se lembra bem deste início e destaca que o foco nunca foi o programa.

A Caravana começou no início de 2004 com toda essa ação pensada. Nessa época o José Trajano mobilizou um grupo de pessoas e, a partir daí, nasceu a Caravana com uma proposta muito clara: vamos levar para as comunidades de baixa renda nointerior do Brasil, em parceria com a UNICEF, atividades esportivas mostrando para crianças e professores como isso pode ser diferente. O programa não vem como uma decorrência, ele vem como um acompanhamento,porque assim você realiza o projeto e dá visibilidade a esse projeto. Não no sentido de visibilidade enquanto marca, mas enquanto método. Fazer com que 
as pessoas cada vez mais entendam que o esporte pode ser visto de uma outra maneira. (SALDANHA, 2016).

O Instituto Esporte e Educação, criado e dirigido por Ana Mozer no final dos anos 1990, quando encerrou sua carreira como atleta, está por trás de toda a metodologia desenvolvida para a Caravana do Esporte, como relata Adriana Saldanha.

Ela formou uma equipe de coordenadores pedagógicos, mestres em educação e em educação física como, por exemplo, o professor João Batista, que estuda o movimento do corpo, com vários livros publicados, e o professor José Elias, ex- preparador físico da seleção feminina de volei, criando uma metodologia com essa visão, de vanguarda naquela época, que pretendia entender e trabalhar o corpo de uma outra forma. Como jornalista eu não tinha nada a ver com isso, mas essa afinidade veio através do movimento do próprio corpo, que a gente muitas vezes carrega, sem perceber ou dar valor. E isso é fascinante, garantir o direito à criança de se conhecer, desenvolver lateralidade, desenvolver o andar, o caminhar (...) e aí veio a junção de atletas, professores, jornalistas, produtores e todo mundo juntou esforços nesse grande movimento para realizar a Caravana. Desde então a Caravana vem se realizando todos os anos, 10 comunidades por ano, sendo que em 2007 a gente agregou arte com música, dança e ritmo, criando a Caravana das Artes. (SALDANHA, 2016)

De acordo com José Trajano, o programa veio junto com essa ação de esporte educacional, como parte integrante do projeto.

É uma coisa diferenteporque hoje, se você for olhar, o projeto é maior do que o programa. Para a televisão era um programa junto com um projeto e o fato de passar na televisão tem suas vantagens, ajuda a ter patrocínio e divulgar o projeto, as pessoas gostam de se ver na televisão e o programa acaba sendo uma espécie de cartão de visitas do projeto, portanto é fundamental que o projeto passe na televisão. Então vai um grupo de atletas e vai também um grupo de artistas, com shows, música e oficinas de arte. Ou seja, ampliou, ganhou um tamanho muito grande. (TRAJANO, 2016)

A realização da Caravana se dá geralmente num campo de várzea, ou numa grande praça, onde possam ser reunidas cerca de 3.200 crianças, além de professores, atletas, técnicos, jornalistas e produtores.

A mobilização e articulação começa em média um ano antes por telefone, e-mail, fotos e informações do próprio município. Com esses elementos a gente vai fazendo todo o mapeamento. A equipe chega na cidade dez dias antes, já sabendo o lugar onde tudo vai acontecer. Em paralelo acontece a formação de professores, tanto em esporte 
educacional, quanto em arte educacional. A ideia é mostrar para esse professor de educação física, que ele pode desenvolver esse olhar para o esporte de uma outra maneira. E não só o professor de educação física, porque no interior do Brasil você não tem professor de educação física, são professores de tudo. Aí você pega esse professor, ou pedagogo, que está na cidade, e trabalha jogos que ele tem condição total de desenvolver com a criança. Ele recebe um livro com o método e vários jogos que ele pode aplicar, além disso a gente tem o site que também é um lugar de conteúdo que ele pode acessar, isso sem contar com a formação que ele recebeem três dias, com 40 horas, onde o professor pode aprender a teoria e a prática do esporte educacional (SALDANHA, 2016).

Toda a ação é documentada por uma equipe de jornalistas e produtores da ESPN Brasil, com o intuito de transformar cada parada da Caravana num programa especial com duração de uma hora, cumprindo com a devida responsabilidade social de um canal de televisão como a ESPN Brasil, mas não só. Outras instituições também investem na "Caravana do Esporte", mostrando que um projeto baseado em esporte e educação, sem qualquer pretensão comercial, sem promover o esporte de alto rendimento e contando apenas com as celebridades do esporte e das artes interessadas em passar essa mensagem positiva, também tem condições de reunir patrocinadores e dar um bom retorno financeiro à emissora.

É um projeto muito do bem, que conseguiu estabelecer uma configuração muito interessante, incentivado pela lei de incentivo ao esporte e pela lei Ruanet. Estamos ancorados nas duas leis como iniciativa privada, com patrocinadores e com uma linha institucional da UNICEF, ESPN, Disney e dois institutos, o Instituto Esporte e Educação, pelo esporte, e o Instituto Mpumalanga, pelas Artes. Mpumalanga é o nome de uma comunidade no interior da África do Sul, que significa, no dialeto local, lugar onde nasce o sol. A gente colocou esse nome porque é algo que desejamos, que esse sol nasça todos os dias e que cada um seja um sol, que possa brilhar pra si e para o próximo. (SALDANHA, 2016)

\section{Considerações finais}

A longevidade do programa Caravana do Esporte nos canais ESPN mostra não apenas a competência da equipe responsável pela produção do programa, mas também a viabilidade de um programa pautado em temas essenciais para o desenvolvimento educacional de um país ainda distante da igualdade e da justiça social. Infelizmente, 
esse não parece ser o foco atual do jornalismo esportivo na grande mídia, como analisa

José Trajano.

As televisões esportivas estão todas iguais de um modo geral.Tem horas que você assiste e não sabe mais qual é uma e qual é a outra. Se você olhar, é um bando de homens sentados no sofá, a tela em Lpassando informações em baixo sobre o assunto, ou o que virá depois, telão e os repórteres entrando ao vivo via internet. Essa fobia pelo ao vivo (tudo tem que ser ao vivo) e assim por diante. Ficou tudo igual, em detrimento dos programas de maior fôlego, melhor conteúdo, maior densidade. A Sportv ainda tem o Sportv repórter, que faz boas coisas. Eles mantém na grade um programa de reportagem, com um jornalismo mais sério, mais investigativo, mais profundo. $\mathrm{Na}$ ESPN Brasil a gente fazia muita coisa. Na minha época o objetivo era mostrar o Brasil. Acho que a gente conseguia mostrar o Brasil com o "Brasil da Copa do Brasil", com o "Histórias do Esporte", com o próprio "Ponta pé Inicial" e até com os esportes radicais a gente mostrava várias coisas do Brasil , começando com o "Triz".Nós tinhamos várias nuances para mostrar o Brasil de várias facetas, de várias formas, mas essa fórmula que todo mundo pegou e se agarrou (não é privilégio de nenhum canal), jogou pra fora o jornalismo que vinha da imprensa escrita, que tinha um pé na antiga "Revista Realidade" , no "Jornal da Tarde" de antigamente, nas grandes matérias dos jornais... esse tipo de jornalismo e de jornalista está acabando, infelizmente. (TRAJANO, 2016)

Nem tudo está perdido. Programas como o Caravana do Esporte resistem, como observa Adriana Saldanha, em nome da diversidade e da qualidade do jornalismo esportivo atual.

Não tem nenhuma TV que abra um espaço para falar sobre educação e esporte. Se abre, abre de uma forma pequena com matérias isoladas. Você permitir, dentro de uma grade de programação, veicular um inédito com mais de três reprises, dentro da ESPN Brasil e da ESPN+, isso é inédito. Eu acho que a gente está perdendo os grandes programas jornalísticos que traziam questionamentos muito importantes. Acho que hoje a gente faz muito evento, mas indaga muito pouco, a gente questiona muito pouco. A gente tinha programas em várias emissoras que saíram da grade e que traziam questionamentos importantes em relação à vida de um atleta, em relação ao esporte de base, em relação à idade mínima para que um atleta seja considerado profissional. É um absurdo isso, um menino não tem condição de escolher, ele não tem maturidade... Como podemos colocá-lo na posição de sustentar uma família? E para fazer isso, na maioria das vezes, o menino para de estudar. Então falta espaço na grade hoje para essas questões, para falar sobre esses assuntos. O importante hoje é mais o dinheiro do que qualquer outra coisa. São os grandes eventos, as grandes copas, os grandes orçamentos. Se pudéssemos voltar no tempo eu manteria uma 
programação mais criteriosa. Mas com uma programação voltada para o mercado, fica impossível. (SALDANHA, 2106)

Em tempos de Olimpíadas e de valores olímpicos, o programa "Caravana do Esporte" mostra que é possível produzir um conteúdo esportivo engajado, voltado para o esporte educacional e promovendo os princípios do olimpismo. Algo que mira numa carência essencial ao brasileiro, sua educação. Exemplos como esse deveriam ser seguidos em nome da elevação do nível de discussão que pode ser propiciada pelo esporte em programas jornalísticos, escapando da norma vigente que prega o esporte comum tema banal, destinado a divertir e entreter um público pouco interessado em sua própria evolução.

\section{Referências}

BARBEIRO, Heródoto; RANGEL, Patrícia. Manual do Jornalismo Esportivo. São Paulo: Editora Contexto, 2006.

BAUDRILLARD, Jean. Sociedade de consumo. Rio de Janeiro: Elfos, 1995.

BOURDIEU, Pierre. Sobre a Televisão. A influência do jornalismo. Os Jogos Olímpicos. Rio de Janeiro: Jorge Zahar Editor, 1997.

BOYLE, Raymond; HAYNES, Richard. Power Play: Sport, the Media and Popular Culture. Harlow: Pearson Education, 2000.

CAMARGO, Vera Regina Toledo. O telejornalismo e o esporte espetáculo. Tese de doutorado, UMESP, São Paulo, 1998.

CASTELLS, Manuel. A Era da Informação. São Paulo, Paz e Terra, 1999.

COUSINEAU, Phil. O Ideal Olímpico e o Herói de Cada Dia. São Paulo: Mercuryo, 2004.

CRISPI, Priscila. "O lugar do esporte na comunicação pública". Revista do Conselho Curador EBC. Julho de 2014, p.11. 
DAMATTA, Roberto. Antropologia do óbvio - Notas em torno do significado social do futebol brasileiro. In: Revista USP 22, 1994, p. 14.

DEBORD, Guy. A Sociedade do Espetáculo. Rio de Janeiro: Contraponto, 1997.

DINES, Alberto. O papel do jornal. Rio de Janeiro: Arte Nova, 1974.

DUPAS, Gilberto. Ética e poder na sociedade da informação. São Paulo: Editora da Unesp, 2000.

GURGEL, Anderson. Desafios do Jornalismo na Era dos Megaeventos Esportivos. In: Motrivivência - Revista de Educação Física, Esporte e Lazer. Santa Catarina, 2009.

HELLER, Agnes. Uma crise global da civilização. In: A crise dos paradigmas em ciências sociais e os desafios para o século XXI. Rio de Janeiro: Contraponto, 1999.

KINKEMA, Kathleen M., HARRIS, Janet C. Media Sport studies: key research and emerging issues. In L.A. Wenner (ed.) MediaSport. London: Routledge, 1998.

MAGUIRE, Joseph. Global Sport: Identities, Societies, Civilizations. Cambridge: Polity, 1999.

MALULY, Luciano. A Notícia Olímpica. Bauru/São Paulo: Intercom/Sudeste, 2013.

MEDINA, Cremilda. Notícia: um produto à venda. São Paulo: Summus, 1988.

PADEIRO, Carlos Henrique. O predomínio do entretenimento no jornalismo esportivo brasileiro. 2015. 126f. Dissertação (Mestrado em Comunicação) - Escola de Comunicações e Artes, Universidade de São Paulo, São Paulo, 2015.

RAMONET, Ignácio. A Tirania da Comunicação. Porto: Campo das Letras, 1999.

ROWE, D. No gain, no game? Media and sport. In: J. Curran and M. Gurevitch (eds) Mass Media and Society, 3rd ed. London: Edward Arnold, 2000.

ROWE, David. Sport, Culture and the Media: The Unruly Trinity. 2nd ed. Maidenhead: Open University Press, 2004.

TUBINO, Manoel José Gomes. O que é Olimpismo. São Paulo: Brasiliense, 2007.

TAMBUCCI, Pascoal Luiz. Esporte e Jornalismo. São Paulo: Cepeusp, 2011. 